\title{
A NUMERICAL MODEL OF THE LAURENTIDE ICE SHEET
}

\section{(Abstract)}

by

James C. Hall

(518 Town Hill Road, New Hartford, CT 06057, U.S.A.)

This paper describes a numerical model of the Laurentide ice sheet of North America, and some of the results derived using it.

The model itself is of a finite-difference type, founded on the basic equations of the physics and thermodynamics of ice. The treatment of climate is by a parametric model (the parameters include a third-order equation (ten terms) on latitude and longitude (varying with time), corrections for elevation, ice albedo, and distance to the edge of the ice sheet), although this could be changed quite easily. The ice-dynamics part of the model includes provision for variation of the flow-law constant with ice temperature, a temperature-profile computation for the ice itself, and provision for varying the sliding at the base of the ice as a function of the nature of the substrate. Isostatic depression and rebound, as well as eustatic sea-level change, are also incorporated in the model. An elementary finite-difference model for the flow of ice in floating ice shelves is also incorporated. The model is, in some respects, vaguely similar to Budd and Smith's (1981), but places greater emphasis on the geomorphic aspects of ice rather than the climatic aspects. It is adaptable to any ice sheet by using an appropriate terrain data base and set of climate parameters.
The paper also describes the results from one set of model runs, simulating the Wisconsin glaciation of North America. These results show that, in general, the model predictions of flow directions and limits agree moderately well with field evidence, but that velocities are somewhat higher than expected $\left(100-1000 \mathrm{~m} \mathrm{a}^{-1}\right)$ on the southern edges of the ice sheet, while stresses, particularly in the centre of the ice sheet, are somewhat less than expected (below $60 \mathrm{kPa}$ for much of the central region). Among other results, the model suggests that it may not be necessary to require "buttressing" marine ice shelves to maintain the main ice sheet and that the location of the edge of the ice sheet responds sensitively to small variations (both in time and space) of climate.

\section{REFERENCE}

Budd, W.F. and I.N. Smith. 1981. The growth and retreat of ice sheets in response to orbital radiation changes. International Association of Hydrological Sciences Publication 131 (Symposium at Canberra 1979 - Sea Level, Ice and Climatic Change), 369-409. 